\title{
High-Speed Visualization of Nanopowder Combustion in Air
}

\author{
F. A. Gubarev ${ }^{*}$, M. S. Klenovskii², L. Li ${ }^{1}$, A. V. Mostovshchikov¹, A. P. Ilyin ${ }^{1}$ \\ 1. Tomsk Polytechnic University \\ 2. Institute of Electron Physics National Academy of Sciences of Ukraine \\ (*) E-mail: gubarevfa@tpu.ru \\ Received: 13/04/2018 Accepted: 10/10/2018 \\ DOI: $10.7149 /$ OPA.51.4.51003
}

\begin{abstract}
:
The paper discusses the methods of high-speed imaging of high-temperature processes in a real time mode: passive registration in the own light, usage of laser illumination, and using the laser monitor. The visualization results of combustion in air of $\mathrm{Al}$ nanopowder and thermite $\mathrm{Al}-\mathrm{Fe}_{2} \mathrm{O}_{3}$ mixture are presented. The perspectives of application of laser monitors in NDE are considered, particularly for the study of laser ignition of thermite mixtures and solid fuels.
\end{abstract}

Key words: aluminum nanopowder, high-temperature combustion, brightness amplification, copper bromide laser, high-speed imaging, laser projection microscope

\section{REFERENCES AND LINKS / REFERENCIAS Y ENLACES}

[1] A. A. Gromov, U. Teipel, Metal Nanopowders: Production, Characterization, and Energetic Applications, Wiley-VCH, Weinheim (2014).

[2] A. P. Il'in, A. V. Mostovshchikov, N. A. Timchenko, "Phase formation sequence in combustion of pressed aluminum nanopowder in air studied by synchrotron radiation," Combust Explo Shock 49, 320-324 (2013)

[3] D. S. Sundaram, V. Yang, E. Zarko, "Combustion of nano aluminum particles (Review)," Combust Explo Shock 51, 173-196 (2015).

[4] D. S. Sundaram, P. Puri, V. Yang, "A general theory of ignition and combustion of nano- and micronsized aluminum particles," Combust Flame 169, 94-109 (2016).

[5] W. H. Hunt, "New directions in aluminum-based P/M materials for automotive applications," Inter J Powd Metal 36, 50-56 (2000).

[6] T. B. Jackson, A. V. Virkar, K. L. More, R. B. Dinwiddie, A. Raymond, R. A. Cutler, "High-thermalconductivity aluminum nitride ceramics: The effect of thermodynamic, kinetic, and microstructural factors," J Am Ceram Soc 80, 1421-1435 (1997).

[7] V.V.Zakorzhevskii, I. P. Borovinskaya, "Combustion synthesis of submicron AlN particles," Inorg Mater 51, 566-571 (2015).

[8] J. Sivan, Y. Haas, "Laser ignition of various pyrotechnic mixtures - an experimental study," Propell Explos Pyrotech 40, 755-758 (2015).

[9] N. M. Bulgakova, A. N. Panchenko, V. P. Zhukov, S. I. Kudryashov, A. Pereira, W. Marine, T. Mocek, A. V. Bulgakov, "Impacts of ambient and ablation plasmas on short- and ultrashort-pulse laser processing of surfaces," Micromachines 5, 1344-1372 (2014).

[10] C. E. Little, Metal Vapor Lasers: Physics, Engineering \& Applications, Chichester: John Willey \& Sons Ltd. (1998).

[11] R. Biswal, G. K. Mishra, P. K. Agrawal, S. V. Nakhe, S. K. Dixit, "Studies on the spectral purity of copperhydrogen bromide laser radiations," Appl Opt 52, 3269-327 (2013).

[12] F. A. Gubarev, L. Li, M. S. Klenovskii, D. V. Shiyanov, "Spatial-temporal gain distribution of a CuBr vapor brightness amplifier," Appl Phys B 122, 284 (2016). 
[13] M. J. Withford, D. J. W. Brown, R. P. Mildren, R. J. Carman, G. D. Marshall, J. A. Piper, "Advances in copper laser technology: kinetic enhancement," Prog Quant Electron 28, 165-196 (2004).

[14] D. N. Astadjov, K. D. Dimitrov, D. R. Jones, V. K. Kirkov, C. E. Little, N. V. Sabotinov, N. K. Vuchkov, “Copper bromide laser of $120 \mathrm{~W}$ average output power," IEEE J. Quantum Electron 33, 705-709 (1997).

[15] A. S. Skripnichenko, A. N. Soldatov, N. A. Yudin, "Method of two-pulse frequency regulation of coppervapor laser parameters," J Russ Las Res 16, 134-137 (1995).

[16] Optical Systems with Brightness Amplifiers, Edited by G.G. Petrash, Moscow: Nauka (1991).

[17] V. M. Batenin, I. I. Klimovskii, L. A. Selezneva, "Research of surfaces of electrodes of a carbon arc during its burning," Doklady Akademii Nauk 303, 857-860 (1988).

[18] D. V. Abramov, S. M. Arakelian, A. F. Galkin, I. I. Klimovskii, A. O. Kucherik, V. G. Prokoshev, "On the possibility of studying the temporal evolution of a surface relief directly during exposure to highpower radiation," Quantum Electron 36, 569-575 (2006).

[19] A. P. Kuznetsov, R. O. Buzhinskij, K. L. Gubskii, A. S. Savjolov, S. A. Sarantsev, A. N. Terekhin, "Visualization of plasma-induced processes by a projection system with a Cu-laser-based brightness amplifier," Plasma Phys Rep 36, 428-437 (2010).

[20] G. S. Evtushenko, M. V. Trigub, F. A. Gubarev, T. G. Evtushenko, S. N. Torgaev, D. V. Shiyanov, "Laser monitor for non-destructive testing of materials and processes shielded by intensive background lighting," Rev Sci Instrum 85, 033111 (2014).

[21] https://www.fastecimaging.com/fastec-hispec-series-high-speed-cameras/.

\section{Introduction}

Nowadays, a number of methods are used for producing new materials, which are associated with the interaction of powerful energy fluxes with a matter or high-temperature combustion processes [1-9]. One of these processes is manufacturing aluminum nitride (AlN) by combustion of aluminum nanopowder in air [1-7]. AlN nanopowder is effectively used in solid propellants, thermites and explosives. Aluminum-based materials offer a number of interesting and potentially high impact commercial opportunities in automotive industry and microelectronics.

To understand the nature of the processes and to control these processes to produce ceramic materials with a specified phase composition and crystalline phase morphology, it is necessary to study thoroughly the mechanism of AlN formation by combustion of aluminum nanopowder in air and the morphology of the synthesized products. High temperatures $\left(\sim 2500^{\circ} \mathrm{C}\right)$ attained during aluminum nanopowder combustion and high reaction rate are the problems that complicate the study. Therefore, there is a need to develop new research methods and techniques, especially for visual control.

Gaseous metal vapor active media have unique characteristics such as high single pass gain, high pulse repetition frequency, operation in a visible spectral region, high average power and ability to control laser radiation parameters [10-15]. This makes these media appropriate for use as brightness amplifiers in laser projection microscopes and laser monitors [16-20]. Emitting at two wavelengths in green $(510.6 \mathrm{~nm})$ and yellow $(578.2 \mathrm{~nm}$ ) spectral regions copper vapor laser was used for the first time to observe the electrodes of carbon arc and was referred to as "laser monitor" [17]. These devices allow observation through the flame, and visualization of the processes shielded by intensive background lighting.

In the paper, we discuss three methods of visual monitoring of self-propagating high-temperature synthesis: passive registration in the own light, usage of laser illumination, and using the laser monitor. We present the visualization results of combustion in air of Al nanopowder and thermite $\mathrm{Al}-\mathrm{Fe}_{2} \mathrm{O}_{3}$ mixture with using of different imaging technique.

\section{Experimental Technique}

Aluminum nanopowder used in the work was produced by electrical explosion of aluminum wire in argon by means of the setup UDP-4G developed in Tomsk Polytechnic University [2]. The activity parameters of the aluminum nanopowder are as follows: the initial oxidation temperature is $450^{\circ} \mathrm{C}$; the oxidation level is $63.8 \%$; the maximum oxidation rate is $0.13 \mathrm{wt} . \% /{ }^{\circ} \mathrm{C}$; the specific heat effect is $4995 \mathrm{~J} / \mathrm{g}$. The particle size distribution is close to the logarithmic normal size with the maximum of $120 \mathrm{~nm}$. We used the samples of 
elongated parallelepiped shape for the purpose of more favourable observation of their surface. The samples were placed on aluminum substrate. To perform the experiments, we take the samples with the weight more than $3 \mathrm{~g}$ to provide two-stage combustion [1]. Ignition of nanopowder samples were provided by open fire from the match.

Fig. 1 depicts the schemes of observation. The images were recorded using a high-speed colour CMOS camera Fastec HiSpec 1 [21]. The dynamic range of the camera is 1600 ISO. The used camera has $2 \mathrm{~Gb}$ internal frame memory and is characterized by the available minimum exposure time of $2 \mu \mathrm{s}$. The temporal resolution is up to $506 \mathrm{fps}$ at full $1280 \times 1024$ spatial resolution and up to $112000 \mathrm{fps}$ at reduced resolution. The maximum recording speed used in the research was 1200 fps to provide enough time for the combustion recording.

In the scheme Fig. 1a, we used the gray filter to weak the bright lighting. The objective is the Navitar DO5095 lens (50 mm with manual focus) mounted directly on the camera.

In the scheme Fig. 1b, DPSS laser with $532 \mathrm{~nm}$ wavelength and $5 \mathrm{~mW}$ average lasing power was used. To illuminate the whole sample we install a diffuser in the path of laser radiation. To cut the broadband illumination we used the colour glass filter.

Fig. 1c shows the scheme of visual control with laser monitor. The superradiance from the CuBr brightness amplifier illuminates the sample. The image amplifier used in this work had gain medium size of $1.5 \mathrm{~cm}$ bore and $40 \mathrm{~cm}$ long. The wavelengths of radiation are $510.6 \mathrm{~nm}(\sim 70 \%)$ and $578.2 \mathrm{~nm}(\sim 30 \%)$. The operation mode of the brightness amplifier was optimised to provide the beam shape close to Gaussian without the dip of intensity in the center [12]. Brightness amplifier operates at $20 \mathrm{kHz}$ pulse repetition frequency with $50 \mathrm{~ns}$ amplified spontaneous emission pulse duration. The average power $14 \mathrm{~mW}(0.7 \mu \mathrm{J}$ pulse energy) was measured when the Ophir PD300 sensor was placed instead of the nanopowder sample. Because of the nanostructure of the aluminum nanopowder, only few percent of the light is reflected back into the brightness amplifier. At 0.1-1 $\mathrm{mW}$ input power the gain of the copper vapor medium is of the order $10^{3}$ [16]. Laser monitor is the system of monochromatic light. Therefore it allows using monochrome camera. Fastec HiSpec 1 camera with monochrome sensor has the dynamic range 3200 ISO [21]. We can expect, that using this camera or another high-speed monochrome camera, the image quality will be better.

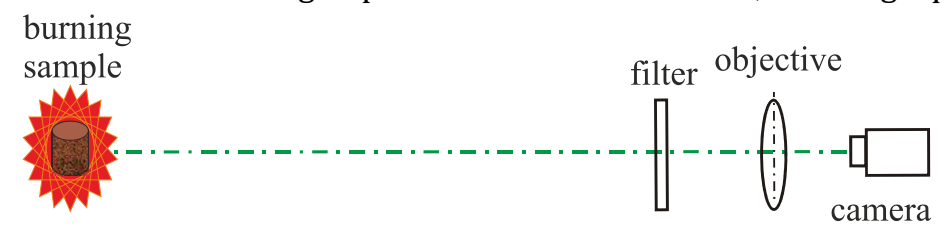

a)
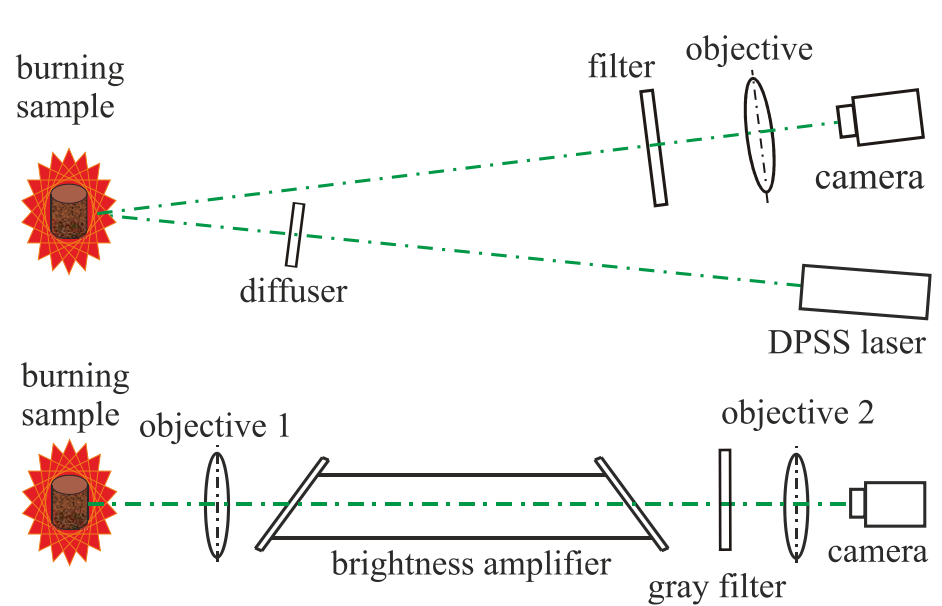

Fig.1. Scheme of visual monitoring in own light (a), with laser illumination (b), and using laser monitor (c).

Objective 1 (Triplet objective lens with the focal length of $80 \mathrm{~mm}$ ) forms an image, which passes through the brightness amplifier and is selectively amplified. To avoid the camera saturation the gray filter is installed. Objective 2 is used to match the beam with the size of the camera matrix. The area under observation in this scheme is about $0.5 \mathrm{~mm}^{2}$. 


\section{Experimental Results}

Fig. 2 shows high-speed imaging of the combustion of nanoAl in air in its own light. We can see from the sequence of images as well as from video that the process of aluminum nanopowder combustion in the air flows in two stages. After ignition (Fig. 2a), the thermal wave's propagation is accompanied by dim lighting. It is the low temperature stage with the temperature about $600-800^{\circ} \mathrm{C}$ [1]. Presumably, the oxidation of aluminum predominates in this phase. Then, the combustion process accelerates and goes into thermal explosion. Temperature increases in up to $2000-2100^{\circ} \mathrm{C}$ (bright lighting) [1]. The wave of the hightemperature combustion propagates along the top of the sample where the surface of the interaction of the powder with the air is larger. The important note for this observation is that second combustion stage starts approximately in the same place of the object as ignition.

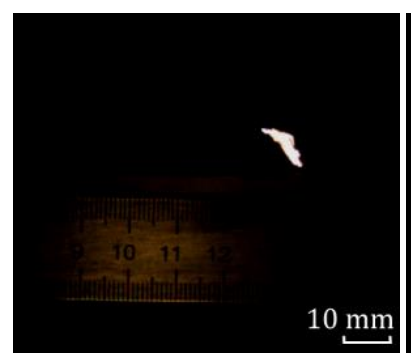

a) $0 \mathrm{~s}$ (ignition)

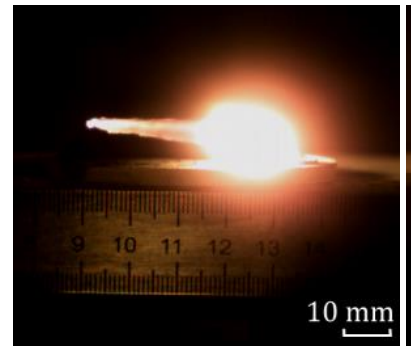

d) $6.9 \mathrm{~s}$

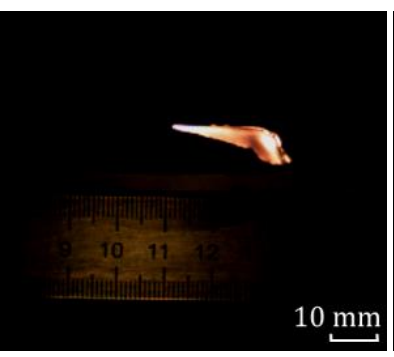

b) $3 \mathrm{~s}$

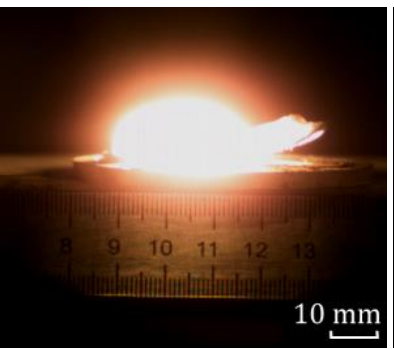

e) $11 \mathrm{~s}$

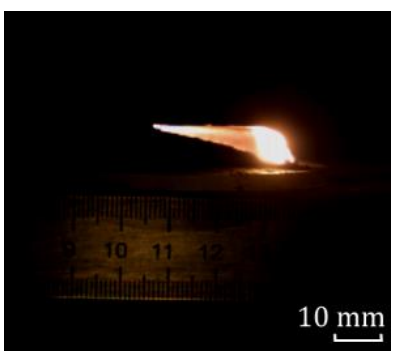

c) $4 \mathrm{~s}$

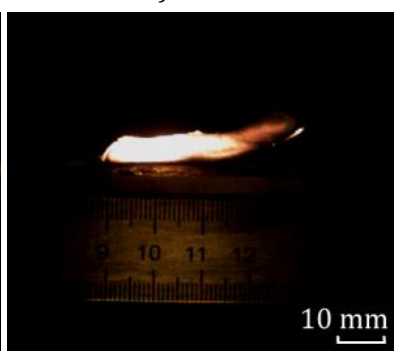

f) $15.3 \mathrm{~s}$

Fig. 2. Frames of the high-speed imaging of aluminum nanopowder combustion in its own light at the different moments of time. a-b - only the low temperature stage of combustion takes place; c-d - the low temperature stage continues at the right side of the sample, the high-temperature wave starts and spreads at the left side of the sample; e - finishing of the high-temperature stage, starting of cooling; f - cooling (see Video 1).

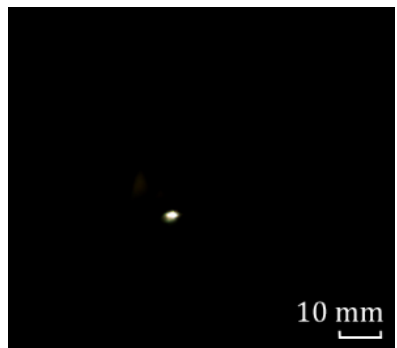

a) $0 \mathrm{~s}$ (ignition)

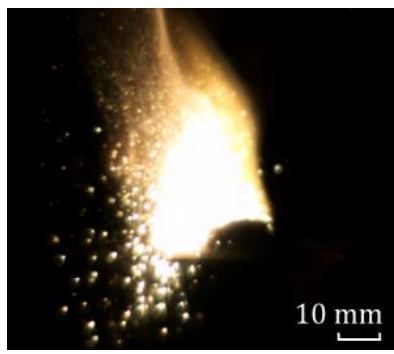

d) $250 \mathrm{~ms}$

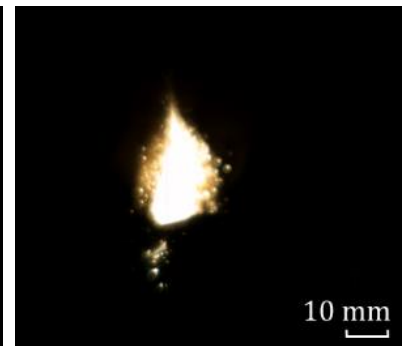

b) $60 \mathrm{~ms}$

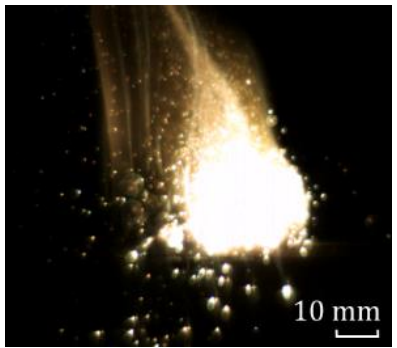

e) $380 \mathrm{~ms}$

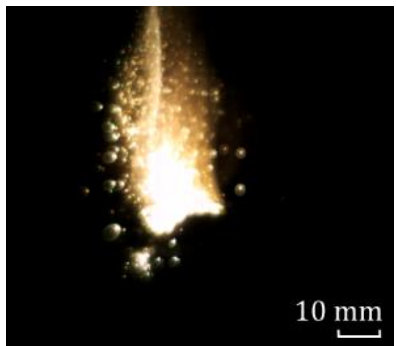

c) $120 \mathrm{~ms}$

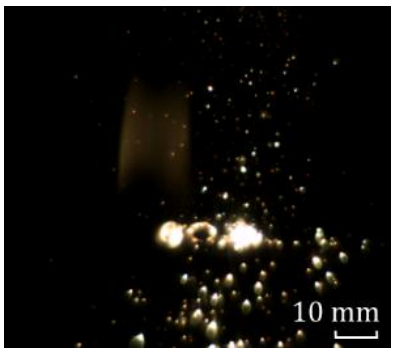

f) $490 \mathrm{~ms}$

Fig. 3. Frames of high-speed imaging of $\mathrm{Al}-\mathrm{Fe}_{2} \mathrm{O}_{3}$ nanopowder combustion in its own light at different moments of time. a - ignition from the match; b-e - propagation of combustion; f - cooling (see Video 2). 
Fig. 3 shows the high-speed imaging of combustion of mixture of nanopowders $\mathrm{Al}-\mathrm{Fe}_{2} \mathrm{O}_{3}$ in air in its own light. On the frames of high-speed recording, we can observe ignition process, propagation of combustion, and cooling. The process of $\mathrm{Al}-\mathrm{Fe}_{2} \mathrm{O}_{3}$ nanopowder combustion is significantly faster than combustion of aluminum nanopowder in the air. In contrast to nanoAl combustion in the air, it is impossible to distinguish two stages of high-temperature combustion observing in the own light. We can see also that $\mathrm{Al}-\mathrm{Fe}_{2} \mathrm{O}_{3}$ nanopowder combustion is accompanied by fast flying-off the products. Because of bright background lighting, the temporal characteristics of processes can be estimated only rough using imaging in its own light.

Method of direct high-speed imaging allows general view observing of the whole sample combustion. It does not allow monitoring the surface of the samples. Using this method, we can only roughly estimate temporal characteristics of the process.

The illumination of the sample by green radiation with simultaneous filtration in the yellow-red region allows being detached from undesirable flare created by the flame. The illumination light reflected from the object has greater intensity than the emission of the burning sample at the wavelength of illumination.

Figs. 4 presents the frames of high-speed recording of nano-Al combustion. We can see the spreading of the first and second combustion waves. The first combustion wave has intensity slightly larger than initial powder; we can clearly observe its spreading. The second wave has much higher intensity. We can observe its spreading but the surface behind it is invisible. Additionally, we can see the cracking of the sample, which is impossible to observe in its own light. Fig. 5 presents the frames of high-speed recording of $\mathrm{Al}_{-}-\mathrm{Fe}_{2} \mathrm{O}_{3}$ nanopowder combustion. Using laser illumination we can study the beginning of combustion, formation of products, products expansion and cooling. The combustion has one distinguishable high-temperature stage. Similar to nanopowder aluminum, the surface of the sample remains almost invisible behind the bright glow.

Based on the results of observation we can conclude that the method of visualization with external laser illumination is good for panoramic view of the processes. It allows estimating roughly stages and velocity of processes, characterize the behavior of the sample combustion. However, to suppress fully the background lighting, it is necessary to increase the power of illumination and decrease the transmission of the filter. The limitation is that lasing power more than 5-10 $\mathrm{mW}$ can influence on the combustion process.

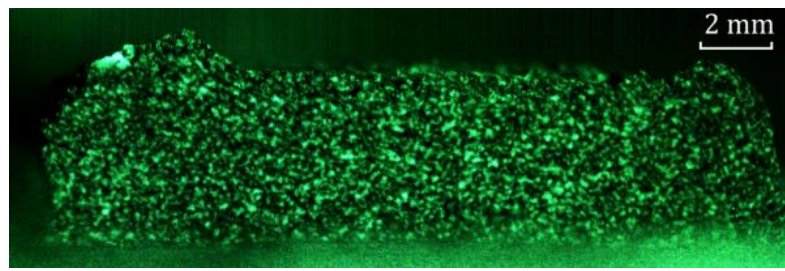

a) $0 \mathrm{~s}$ (ignition)

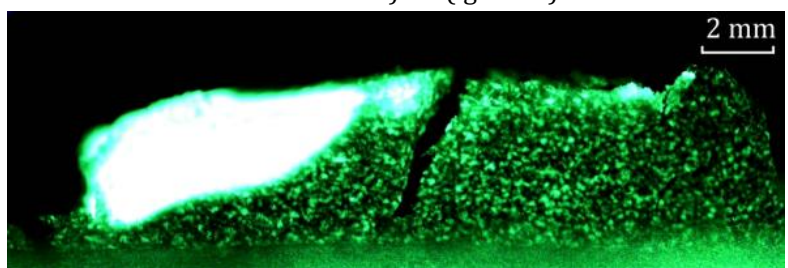

c) $1.35 \mathrm{~s}$

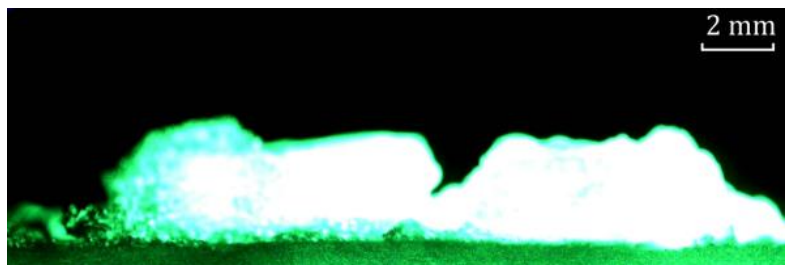

e) $3.03 \mathrm{~s}$

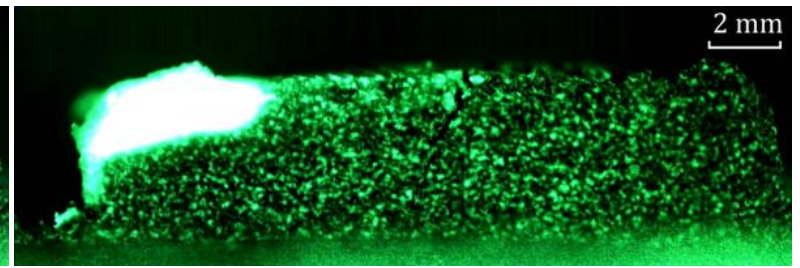

b) $0.8 \mathrm{~s}$

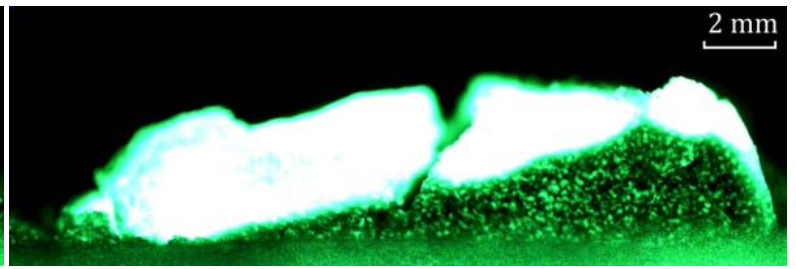

d) $2 \mathrm{~s}$

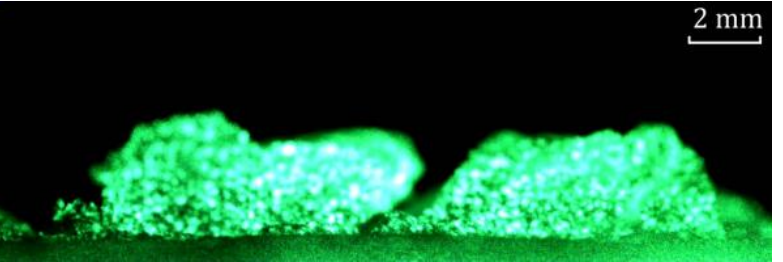

f) $4.9 \mathrm{~s}$

Fig. 4. Frames of the high-speed imaging of Al nanopowder combustion in air with $532 \mathrm{~nm}$ laser illumination. a - ignition, b-d spreading of the first and second combustion waves, e-f - cooling (see Video 3). 

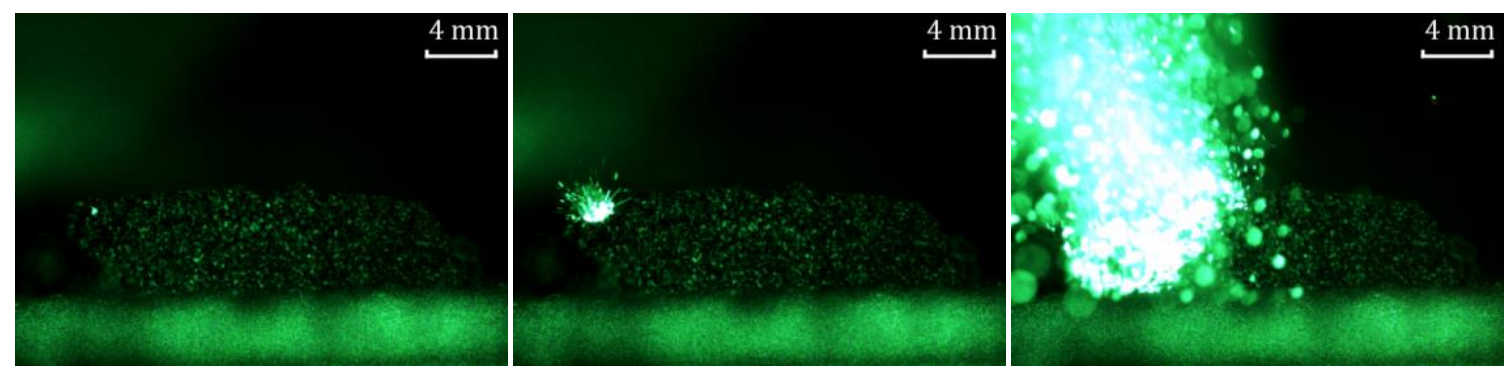

a) $0 \mathrm{~s}$ (ignition)

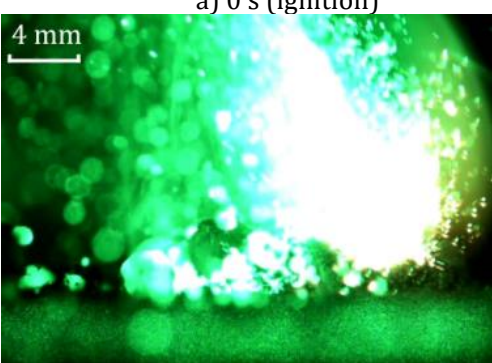

d) $280 \mathrm{~ms}$ b) $5.5 \mathrm{~ms}$

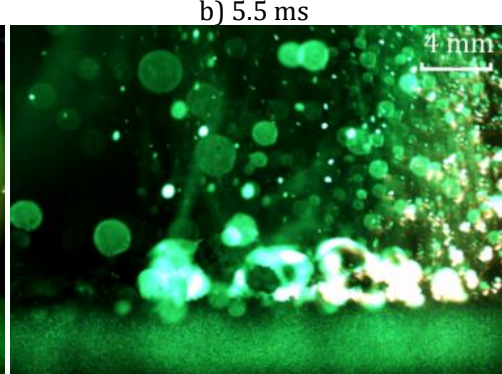

e) $400 \mathrm{~ms}$ c) $120 \mathrm{~ms}$

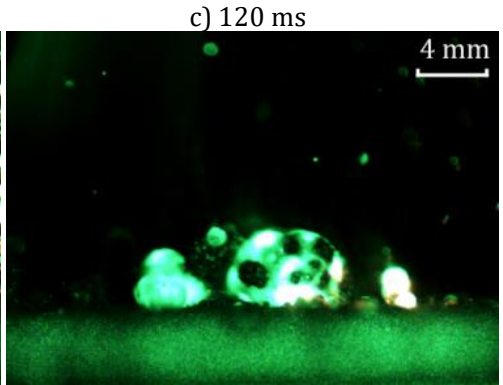

f) $470 \mathrm{~ms}$

Fig. 5. Frames of high-speed imaging of $\mathrm{Al}-\mathrm{Fe}_{2} \mathrm{O}_{3}$ nanopowder combustion in air with $532 \mathrm{~nm}$ laser illumination. a - ignition, b-d spreading of the combustion waves, e-f - cooling (see $\underline{\text { Video } 4)}$

The advantage of active optical systems with metal vapor brightness amplifiers is the possibility of observing the processes through the broadband background lighting [17-20]. According to [16,20], the plasma will remain transparent to the laser monitor as long as the energy exposure concentrated in the emission spectrum of the brightness amplifier does not exceed its self-noise i.e. the amplified spontaneous emission. The estimates of the maximum brightness temperature of the background lighting source, which still allows the observation of the object using a laser monitor, were made in [20] for the gas discharge tube of $5 \mathrm{~cm}$ bore. The estimates show that the brightness temperature of the background radiation can reach $45,000 \mathrm{~K}$. Moreover, the laser monitor is a microscopic system allowing observation of objects with a size up to $\sim 800 \mathrm{~nm}[20]$. In the present work, the spatial resolution is $\sim 5 \mu \mathrm{m}$.

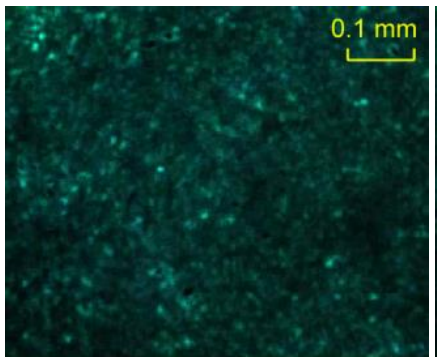

a) $0 \mathrm{~s}$ (recording start)

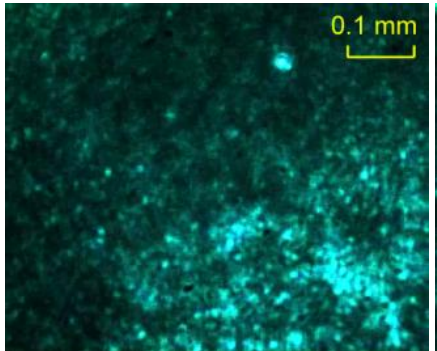

d) $0.14 \mathrm{~s}$

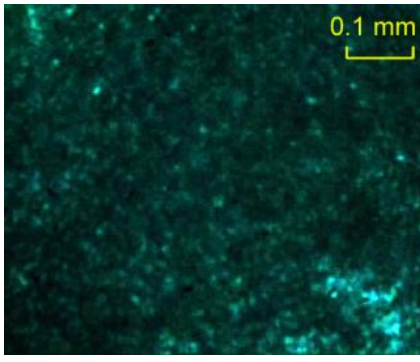

b) $0.06 \mathrm{~s}$

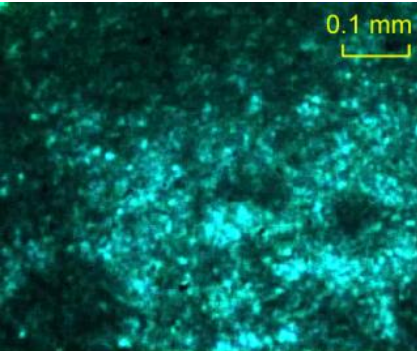

e) $0.2 \mathrm{~s}$

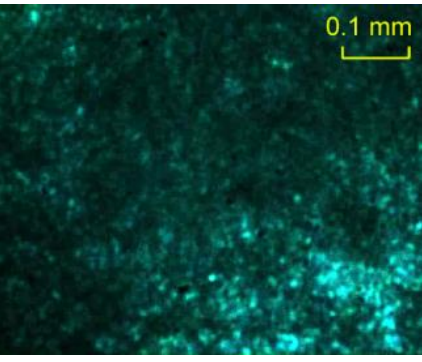

c) $0.1 \mathrm{~s}$

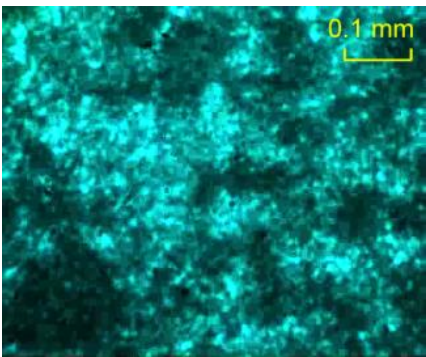

f) $0.32 \mathrm{~s}$

Fig. 6. Images of thermal explosion process of aluminum nanopowder (second stage) obtained by the laser monitor at different moments of time. The speed of the combustion front propagation is $1.88 \mathrm{~mm} / \mathrm{s}$ (see Video 5 )

Fig. 6 presents the frames of high-speed recording of the second stage nanoAl combustion. We can observe the surface changes, particularly changing of reflection coefficient of the surface. In addition, we can measure the speed of the combustion wave propagation. For the presented in Fig. 6 sample it is $1.4 \mathrm{~mm} / \mathrm{s}$. 
In general, the second wave propagation velocity ranged from 0.6 to $2.9 \mathrm{~mm} / \mathrm{s}$ depending on the nanopowder pressing when the samples are formed.

Fig. 7 presents the frames of high-speed recording of $\mathrm{Al}-\mathrm{Fe}_{2} \mathrm{O}_{3}$ nanopowder combustion using the laser monitor. We can observe the formation of spherical products, their movement. As previously, we can estimate the heating wave propagation velocity (from 17.4 to $36.1 \mathrm{~mm} / \mathrm{s}$ for given samples). In contrast to other methods of visualization, we can provide a microscopic magnification and observe the sample in more detail.

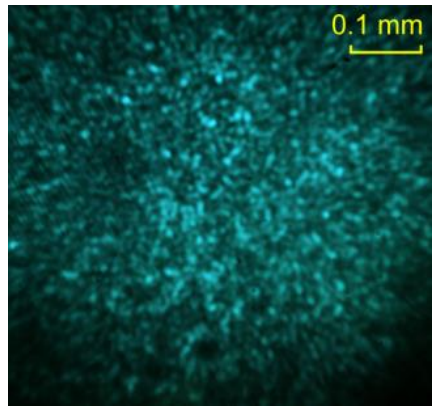

a) $0 \mathrm{~s}$

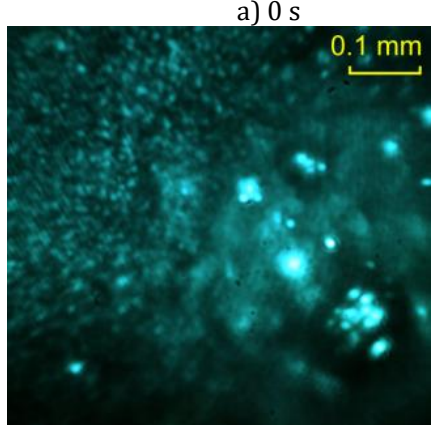

d) $9 \mathrm{~ms}$

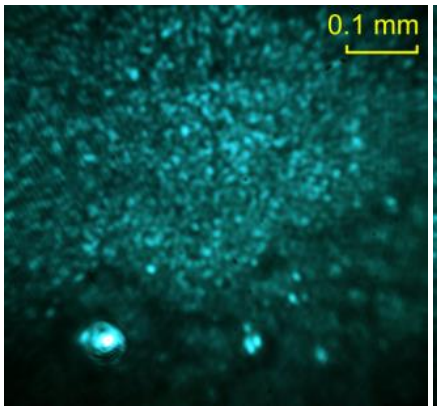

b) $5 \mathrm{~ms}$

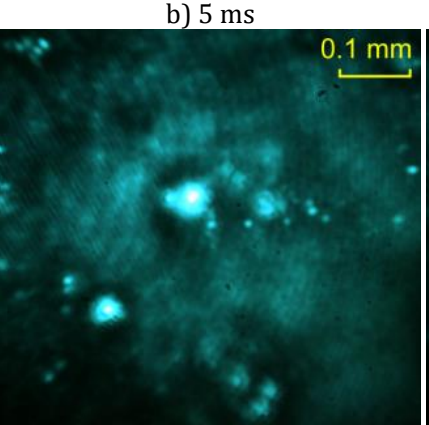

e) $15 \mathrm{~ms}$

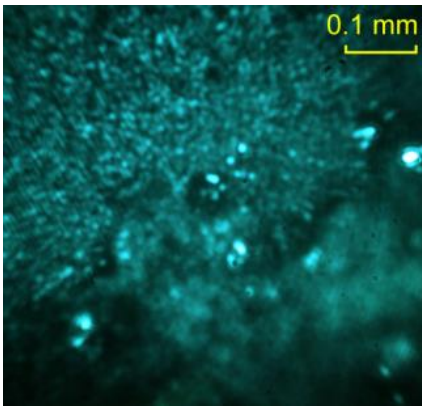

c) $7 \mathrm{~ms}$

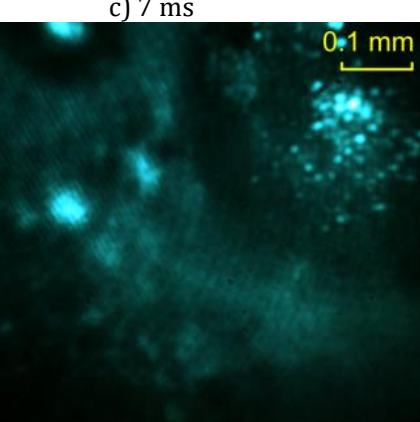

f) $23 \mathrm{~ms}$

Fig. 7. Frames of high-speed imaging of $\mathrm{Al}-\mathrm{Fe}_{2} \mathrm{O}_{3}$ nanopowder combustion obtained by the laser monitor at different moments of time. Figure (a) is the moment just before the visible modification of the surface (see Video 6 )

\section{Conclusions}

We constructed the optical system with brightness amplification (laser monitor) to observe the nanopowders combustion in a real time. The system allows filtering out the background lighting of the flame and enables high time-resolved recording of the process. The results of monitoring the aluminum nitride synthesis through the combustion of aluminum nanopowder in the air and thermite mixture $\mathrm{Al}-\mathrm{Fe}_{2} \mathrm{O}_{3}$ combustion are presented.

We compare the application of laser monitor with other techniques, particularly passive registration in the own light, and usage of laser illumination. We can conclude that all discussed methods complement each other. Application of each of them depends on the task. Passive registration in the own light and laser illumination are well suited for panoramic observation. The advantage of usage of a laser monitor is full filtering out the background lighting and large magnification.

The obtained results indicate the potential of the method, which employs the laser monitor to observe the formation of nanoparticle based microstructures. The considered method allowed gaining more information about staging of the product microstructure formation, particularly to trace the processes during combustion and measure their time parameters.

\section{Acknowledgements}

The research is carried out at Tomsk Polytechnic University within the framework of Tomsk Polytechnic University Competitiveness Enhancement Program and supported by The Ministry of Education and Science of the Russian Federation, Project No 11.1928.2017/4.6. 